\title{
LITHICS BASICS
}

Archaeologists utilize four main sources of information about how stone tools were made and used. These include mechanical studies, experimental archaeology, ethnoarchaeology, and contextual clues from the archaeological record. Mechanical studies investigate the specific physical processes involved in tool production and wear. Experimental archaeology attempts to reproduce prehistoric tools and tool uses under controlled conditions. Ethnoarchaeology develops models for archaeological lithic variability by studying stone tool use by contemporary humans. Finally, contextual clues are patterns of association among stone tools and other residues in the archaeological record. This chapter pulls together insights from these sources to provide a basic introduction to lithic technology. It reviews the main descriptive categories of stone tools and their higher-order groupings as recognized by archaeologists. It also provides a brief overview of the major interpretive concepts in lithic analysis.

\section{MECHANICS OF STONE TOOL TECHNOLOGY}

Stone tools are shaped mainly by fracture and abrasion. Both of these processes involve an objective piece being loaded by an indenter until it "fails." Archaeologists' terms for conchoidal fracture products differ from those used in mechanics (Table 2.I). In lithic technology, the objective piece is called a core or a flake-tool. Force, or load, is transmitted by a hammerstone. The fracture products are called flakes or, collectively, débitage (French for "waste"). 
Table 2.I. Essential Concepts in Fracture Mechanics, Flintknapping, and Lithic Analysis

\begin{tabular}{|c|c|c|}
\hline Definition & Fracture Mechanics & Flintknapping \& Lithic Analysis \\
\hline Object that transmits load & Indenter & Hammer, hammerstone, percussor \\
\hline Object that fails under load & Objective piece & Core, flake-tool \\
\hline Fracture product & Detached piece & Flake, flake fragment \\
\hline
\end{tabular}

\section{Fracture}

Fracture refers to a cleavage plane that forms when a brittle material breaks. Most Paleolithic and Neolithic stone tools were shaped by controlled conchoidal fracture. Conchoidal fractures form when compressive loading stress exceeds the tensile and compressive strength of a brittle material (Cotterell and Kamminga I987). Conchoidal fractures occur in rocks that are both brittle and isotropic. Isotropy is the quality of responding to load equally in any direction.

Glass is a brittle isotropic material often used to research conchoidal fracture. Much of what we know about the mechanical basis of stone tool production comes from experiments investigating aspects of conchoidal fracture mechanics in glass (for an overview, see Dibble and Rezek 2009). Most of the conchoidally fracturing rocks shaped by prehistoric humans were cryptocrystalline silicates, rocks consisting mainly of quartz crystals that are too small to be seen with the naked eye. The most common such rocks used in the Levant were chert and flint, but prehistoric humans also used nonsilicate rocks (limestone and basalt), as well as noncrystalline rocks (obsidian or volcanic glass) and minerals (quartz crystals). Most lithic materials used as hammerstones are tough rocks, such as varieties of basalt, limestone, and quartzite that resist fracture initiation.

Much of the variability in conchoidal fracture arises during the initiation and termination of the fracture (Figure 2.I.a-b). Hertzian initiations begin when compressive force from an indenter creates a cone-like fracture (a "Hertzian cone") on the surface of the core. This fracture propagates under the side of the core, detaching itself with the resulting flake. Bending initiations occur when the edge of a stone artifact is loaded in such a way that the points of maximum compressive and tensile stresses are separate from one another. When this 


\section{a. Fracture Initiations}

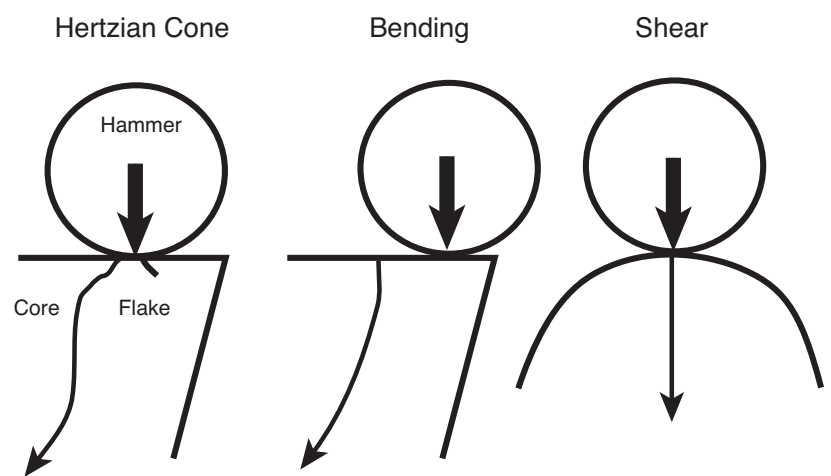

b. Fracture Terminations

Feather

Step

Hinge

Plunging
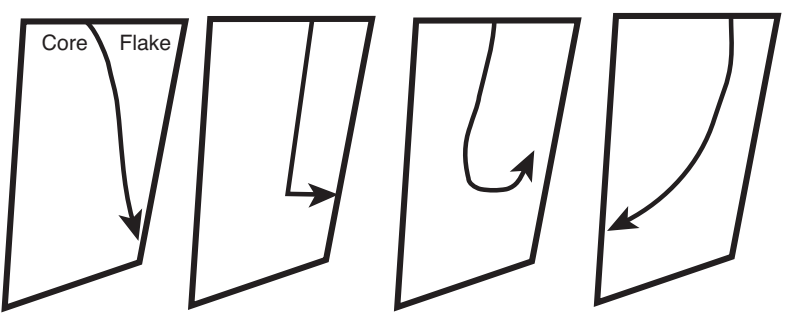

\section{c. Abrasion Mechanics}

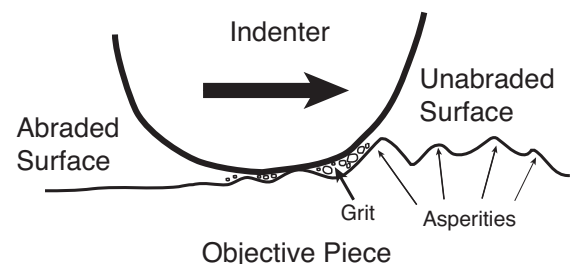

FIGURE 2.I. Conchoidal fracture initiation (top) and termination (middle), and abrasion mechanics (bottom).

happens, a fracture can form in an area under tensile stress located some distance from the point where the indenter comes in contact with the objective piece. Shear initiations occur when compressive stress creates a flat planar fracture directly under the indenter. Termination 
occurs when an expanding flake intersects the surface of the core. Fracture terminations are classified as "feather," "step," "hinge," and "plunging/overshot," depending on their trajectories and shapes in profile view. Fracture propagation (its length and trajectory) depends on many factors, including the structure of the rock (large versus small crystals, inclusions, and bedding planes) the morphology of the core surface, the amount of load and the rate at which it is applied, and the physical properties of the indenter and the degree to which the rock sample was immobilized during fracture propagation.

Archaeologists employ two main sets of contextual clues when reconstructing the specific patterns of fracture used in prehistory. The first of these involves reconstructing fracture propagation trajectories from the fissures, undulations, and other phenomena left on the fracture surfaces. The second is refitting analysis in which archaeologists reassemble artifacts split by fractures. Complex sets of such "refits" can shed light on the sequence by which a rock was modified by successive fractures.

\section{Abrasion}

Abrasion is damage that results from sliding contact between a rock and another surface. This sliding contact creates compressive and bending stresses on the small projections ("asperities") on the stone surface (Cotterell and Kamminga I990: I 5 I-I 59). As these projections are dislodged, they are dragged across the stone surface, creating pits and scratches ("striations") that in turn create additional asperities (Figure 2.Ic). Abrasion can be accelerated by several methods: (I) by sliding the stone tool surface against harder, coarser materials; (2) by introducing hard, angular grit or sand between the tool and another surface; and (3) by using percussion or some other shaping process to roughen and weaken the surface of the tool. Abrasion processes can be altered by the addition of lubricating agents (e.g., water or oil) so that a smoothed or "polished" surface is created. Such polished edges lose less energy to friction during contact with worked materials, improving their cutting effectiveness. In many parts of the world, the edges of stone tools were (ground) polished to improve their cutting effectiveness. 


\section{Flintknapping}

Many of the terms archaeologists use to describe stone tool production are borrowed from flintknapping. Historic flintknappers were craftsmen who produced gunflints, but flintknapping now refers to efforts to make and use replicas of prehistoric stone tools (Whittaker 1994). François Bordes (1969), Louis Leakey (1960), Don Crabtree (1972), and other twentieth-century archaeologists often described their own flintknapping and tool use experiments and used their impressions of the results to guide archaeological interpretations (Johnson I978). The most archaeologically important flintknapping terms refer to different methods for initiating fractures (Figure 2.2). Hard-hammer and softhammer percussion refer to fracture initiation achieved by striking a core with an indenter made of either stone or metal ("hard-hammer") or bone, antler, or wood ("soft-hammer"). Pressure flaking refers to fracture initiation by slowly increasing loading with either a hard or soft indenter. Indirect percussion is a technique in which a knapper initiates a fracture by using a punch to focus energy from a hammerstone or some other percussor. Bipolar percussion involves initiating shear fractures by crushing a core between two stones. The anvil technique involves a knapper striking a core against a stationary stone percussor.

Modern-day flintknappers often use thermal alteration ("heat treatment") to improve the fracture and abrasion properties of a rock. Heating crystalline silicate rocks to $400-500^{\circ} \mathrm{C}$ and then slowly cooling them causes cracks to form in quartz crystals (Beauchamp and Purdy I986, Inizan and Tixier 2000). These cracks weaken the rock, reducing the amount of force necessary to initiate and propagate a fracture. When such heat-treated rocks are knapped, fractures that would otherwise have passed around rock crystals instead propagate through them. Consequently, freshly knapped surfaces of heat-treated rocks are more brightly reflective (lustrous) than samples of the same rock that have not been thermally altered. Thermal alteration also usually changes the color of the rock, but this quality varies with rock chemistry. Until recently, thermal treatment was thought to be a recent (i.e., Late Pleistocene or Holocene age) phenomenon, but the practice is now known from later Middle Pleistocene contexts in southern Africa (Brown et al. 2009). 


\section{KEY DESCRIPTIVE CONCEPTS IN ARCHAEOLOGICAL LITHIC ANALYSIS}

Archaeological lithic analysis uses specialized terminology to describe stone tools and lithic variability (Brézillon I977, Inizan et al. I999). The following sections review the terms and related concepts from lithic analysis that are germane to Levantine Paleolithic and Neolithic stone tools.

\section{Basic Terms for Lithic Artifacts}

Most stone tools are created by initiating a fracture in a piece of rock by striking it with a hammerstone (Figure 2.3). The pieces of rock detached by conchoidal fracture are called flakes, and the rock from which they are detached is called a core. Archaeologists often use the French term débitage to refer collectively to unretouched flakes and flake fragments. Retouched tools are flakes or other detached pieces whose edges feature contiguous and overlapping clusters of small flake scars (retouch). Flintknappers retouch edges either to change the shape of the edge or to resharpen an edge dulled from use. Many archaeologists use the terms "tools" and "retouched tools" synonymously, even though ethnography and microwear analysis of archaeological specimens all show that people used flakes without retouching them. Some archaeologists also distinguish cores with seemingly use-related retouch and/or wear on some part of their circumference as "coretools."

To depict stone tools, lithic analysts have preferred to use line art or drawings instead of photography. This is because many stone tools are either highly reflective or partly translucent. Digital image processing is leading to the increased use of photography, but the overwhelming majority of stone tools are shown in the archaeological literature as line drawings (see Box 2.I).

The major categories of archaeological stone tools are pounded pieces, cores, flakes and flake fragments, retouched tools, or groundstone tools.

\section{Pounded Pieces}

Pounded pieces are artifacts shaped by percussion. The damage caused by this percussion is called comminution - multiple overlapping, 


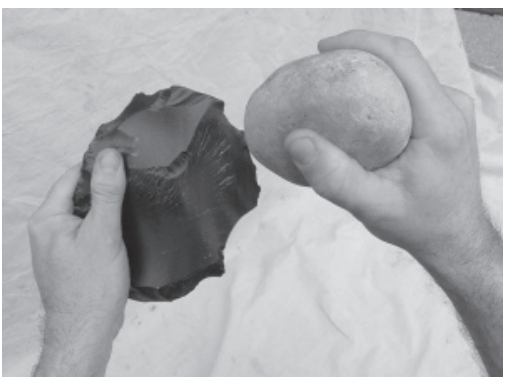

a. Hard hammer percussion

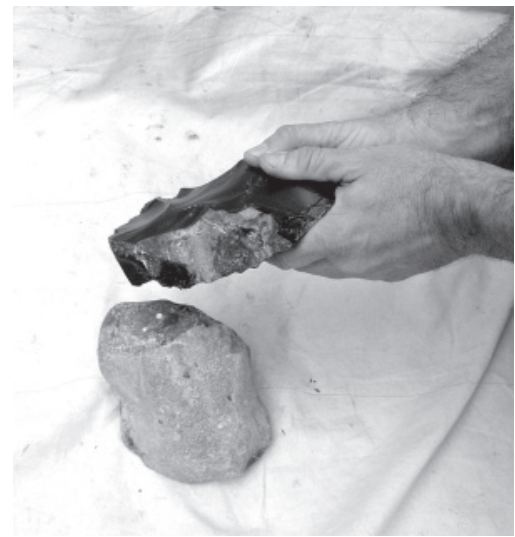

c. Anvil technique

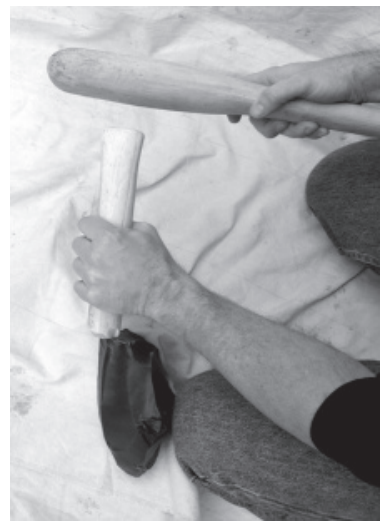

e. Indirect percussion

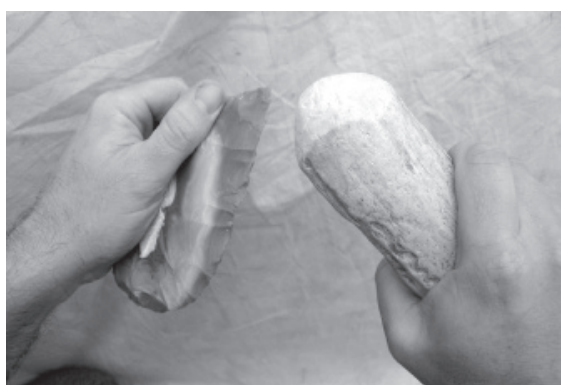

b. Soft hammer percussion

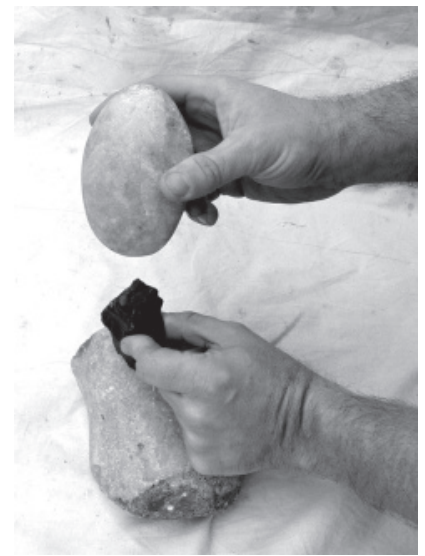

d. Bipolar technique

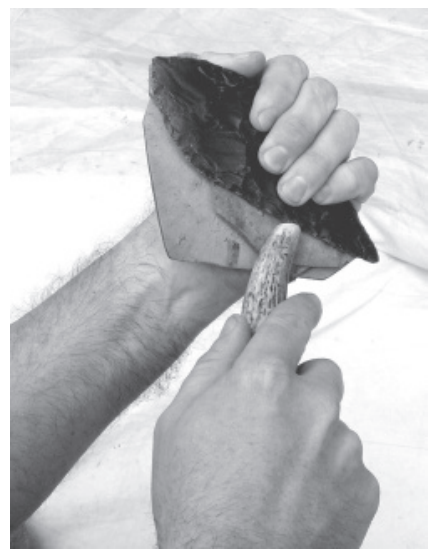

f. Pressure flaking

FIGURE 2.2. Knapping techniques. 


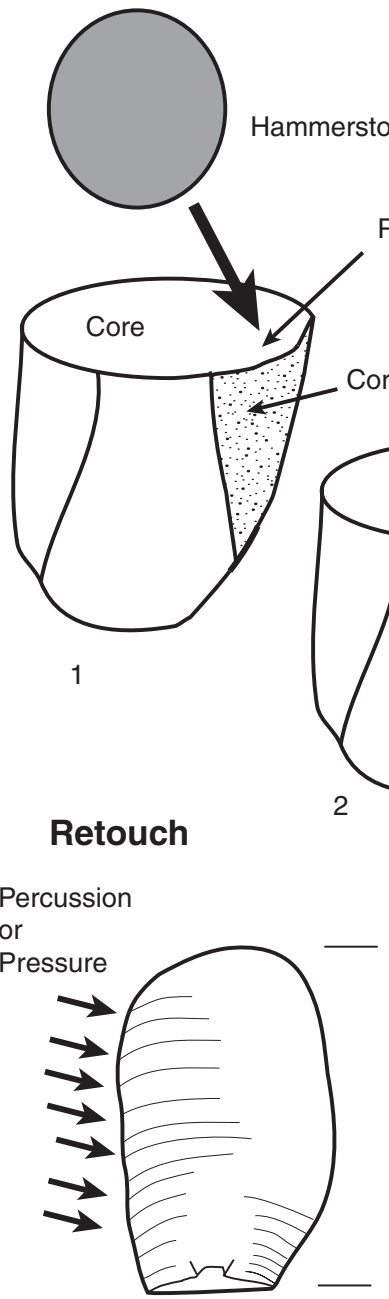

Flake Ventral Surface (Fresh Fracture Surface)

\section{Flake Production}

Point of Fracture Initiation

Fracture Termination

Fracture

Propagation

3

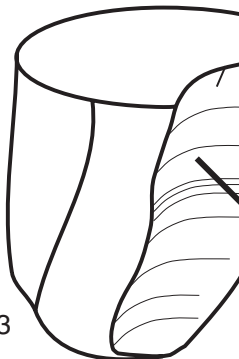

Flake
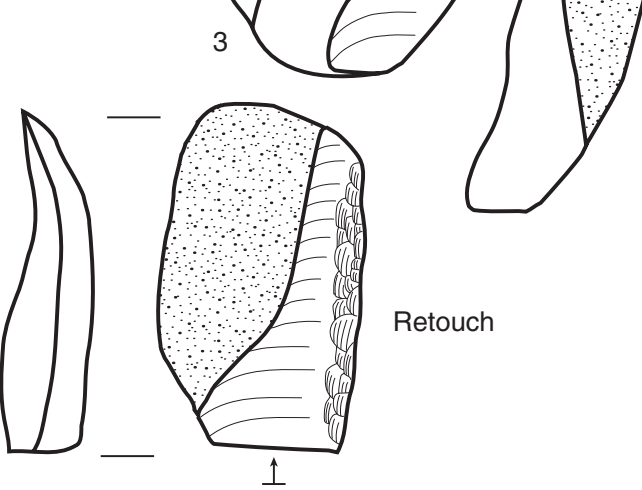

Retouch

Flake Flake Dorsal Surface

Profile (Former Core Exterior)

FIGURE 2.3. Knapping basics: flake production (top), retouch (bottom).

intersecting, and incompletely propagated fractures. Hammerstones and pitted stones are the most common archaeological pounded pieces. Hammerstones are usually spherical or subspherical and weigh less than $2 \mathrm{~kg}$. Their most distinctive features are convex or flat concentrations of crushing and other damage resulting from their use as indenters against other rocks. Hammerstones used by modern 


\section{BOX 2.I LITHIC ILLUSTRATION}

All of the artifact illustrations in this book are redraftings of original artwork from other sources. The literary source and (where possible) original archaeological provenience of each illustrated artifact are indicated in the figure caption. To interpret these drawings, one must understand basic archaeological conventions for drawing and orienting lithic artifacts.

Conventions for drawing lithic artifacts follow most of the principles set forth in Addington (1986) (see Figure 2.4). Cortexcovered surfaces of cores and flakes are indicated by patterns of ink dots called stippling. The edges of fracture scars on core and flake surfaces are indicated by solid lines. These lines begin and end at either the edge of the artifact, another fracture scar outline, or the edge of a cortical surface.

In schematic drawings of cores and flakes, fracture directionality is indicated by placing arrows on the flake scars. Arrows with a circle at the bottom indicate a flake scar that retains the negative impression of a Hertzian cone. Simple arrows indicate that a flake scar lacks a visible point of fracture initiation, but that its propagation trajectory can be inferred from undulations and fissures. Cross-section drawings are indicated in outline and by a solid gray filling. In some cases, a hybrid profile/section drawing on which the working edge is indicated by a thick black line running across the section view is used. Lateral breaks are indicated by sets of short lines at either end of the break and extending away from the drawing in the direction that the complete artifact would have extended. Solid black filling indicates ground and polished surfaces on cores and retouched flakes. Burin removals (see main text) are indicated by arrows pointing to their point of fracture initiation.

This work differs from most conventional drawings of lithic artifacts in that it does not fill flake scars with radial lines. Most formal drawings of cores and flake points use a series of concentric radial lines to indicate the direction of fracture propagation. The convex sides of these lines bulge away from the inferred point of fracture initiation. The extent and spacing of radial lines are also used to convey an impression of shading and three-dimensionality. Radial lines are not used in this book for three reasons. First, 
scar directionality can usually be indicated when necessary by a single arrow. This follows Edward Tufte's (I990) guiding principle for scientific illustration: "maximum information, minimum ink." Secondly, by not cluttering artifact drawings with radial lines, the resulting images are more similar to how lithic artifacts actually appear. Finally, there is so much variability in the ways in which different artists use radial lines, not using them establishes a stylistic consistency for the illustrations in this book.

Stone tools are shown in standardized orientations in drawings and photographs. This allows lithic analysts to use a standard set of terms (i.e., dorsal, ventral, distal, proximal, medial, lateral, etc.) for analogous parts of tools. Unretouched flakes are shown with their striking platform in the proximal position (see main text). Cores are shown with their longest axis usually treated as the distal-proximal axis and the least modified of their surfaces treated as the ventral surface. Retouched tools that still retain remnants of their dorsal and ventral surfaces are oriented the same way as unretouched flakes. Retouched tools that no longer retain evidence of a striking platform are oriented with their longest morphological axis aligned disto-proximally. A few exceptions to these orientations reflect pre-existing archaeological conventions. In the illustrations for this book, the proximal part of the tool is placed in the lowermost (" 6 o'clock") position.

Most artifacts are drawn in at least two views. Minimally, these usually are a plan view of the dorsal face and either a profile (side) view or a cross-section. This is done to give an impression of the artifact's three-dimensional shape. Short lines positioned at either the sides or ends of drawings indicate different views of the same object. Profile/section views are arranged around plan views so that the dorsal face remains closest to the corresponding edge of the plan view (i.e., the "American" convention) (Aprahamian 200I). Ventral flake surfaces are rarely illustrated unless they are retouched and unless they differ from the dorsal surface in some significant way. A five- or ten-centimeter scale indicates artifact size. Wherever possible in this work, illustrations of actual artifacts have been reproduced at full (I00\%) scale. The principal exceptions to this are for relatively large core tools. 
The particular artifacts illustrated in this work were selected for their representative value. That is, a conscious effort was made to find objects that were typical for a given artifact-type and for artifacts from a wide range of contexts.

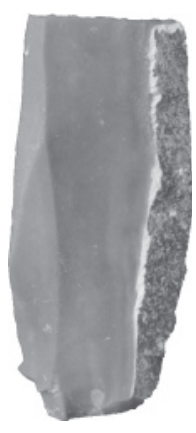

Photograph (Dorsal plan view)

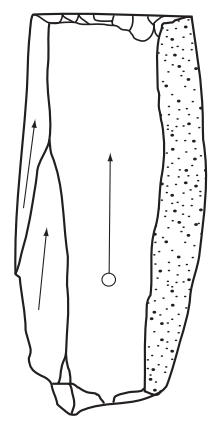

Scar borders, directionality \& cortex
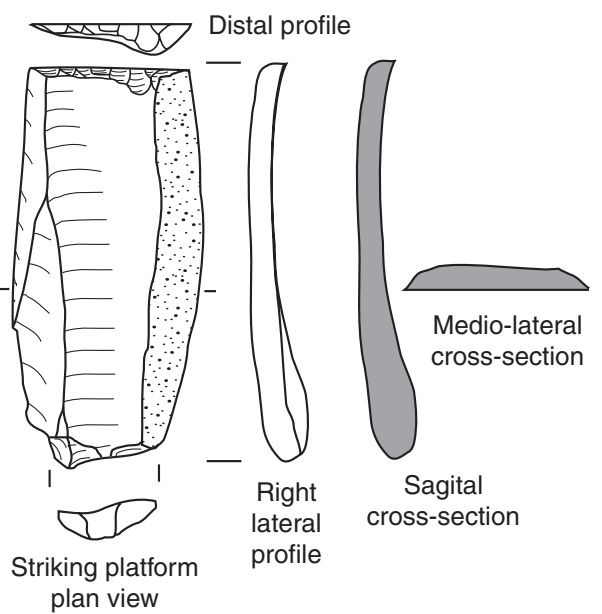

Radial Lines

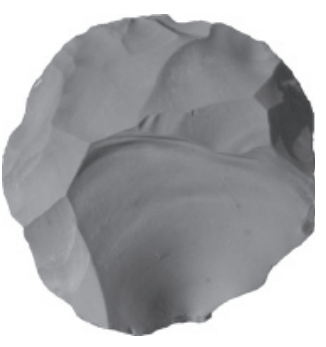

Photograph (Dorsal plan view)

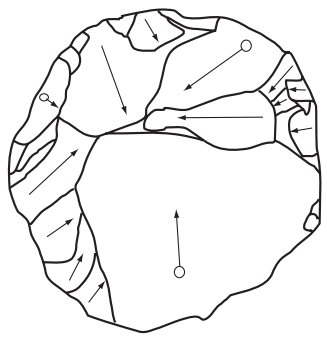

Scar borders, directionality

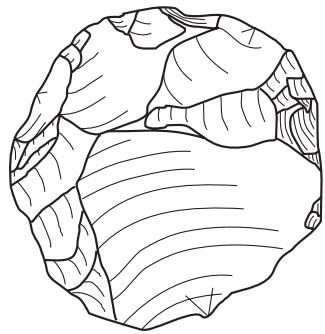

Radial lines

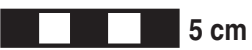

FIGURE 2.4. Conventions for illustrating flaked stone artifacts.

flintknappers often exhibit one or more discrete patches of comminution. Hammerstones used for repetitive pounding on flat surfaces (as occurs when shaping non-conchoidally fracturing rocks by percussion) often exhibit a ring of comminution running around their circumference. This damage is the result of the hammerstone being rotated axially during use. Pitted stones (also called "anvils") are usually 
tabular or plano-convex in cross section. Their most distinctive features are one or more sizeable concavities formed by repeated percussion and the resulting crushing damage.

\section{Cores}

Cores are rocks featuring concavities left by the flake detachment ("flake scars") above a certain size threshold (Figure 2.5). Most archaeologists require there to be at least one flake scar longer than $20 \mathrm{~mm}$ for an artifact to be considered a core. The working edges of most cores are defined by the presence of two intersecting surfaces, a striking platform surface and a flake-release surface. The striking platform surface is the one on which fractures are initiated. The flake-release surface is one beneath which fractures propagate. Many cores were selected for use from nodules excavated from bedrock or clasts (rocks rounded by alluvial processes). Both rocks are covered by weathered surfaces called cortex. As cores are reduced, the proportion of their surface covered by cortex decreases.

The major core types associated with particular phases of Levantine prehistory are discussed in Chapters 3 through 7. For making comparisons between cores from different periods, this book employs a core typology recently proposed by Conard and colleagues (2004). This typology recognizes three major core types (inclined, parallel, and platform), each of which has distinctive geometric and technological characteristics (Table 2.2). On inclined cores, flake-release and striking platform surfaces are interchangeable and exploited roughly equally. Parallel cores have a hierarchy of flake-release and striking platform surfaces that are exploited differently. Platform cores have flakes removed in succession from only one flake-release surface. Although originally intended for use in describing whole artifacts, the key differences in this simplified core typology are applicable to individual working edges (Figure 2.6). In theory, a single artifact could preserve worked edges exhibiting more than one of these configurations. It is also important to remember that individual cores may have shifted from one to another of these typological categories prior to being discarded.

\section{Flakes and Flake Fragments}

Flakes and flake fragments are products of conchoidal fracture. Most flakes and flake fragments are divided by the fracture plane into a 


\section{Striking Platform Surface}

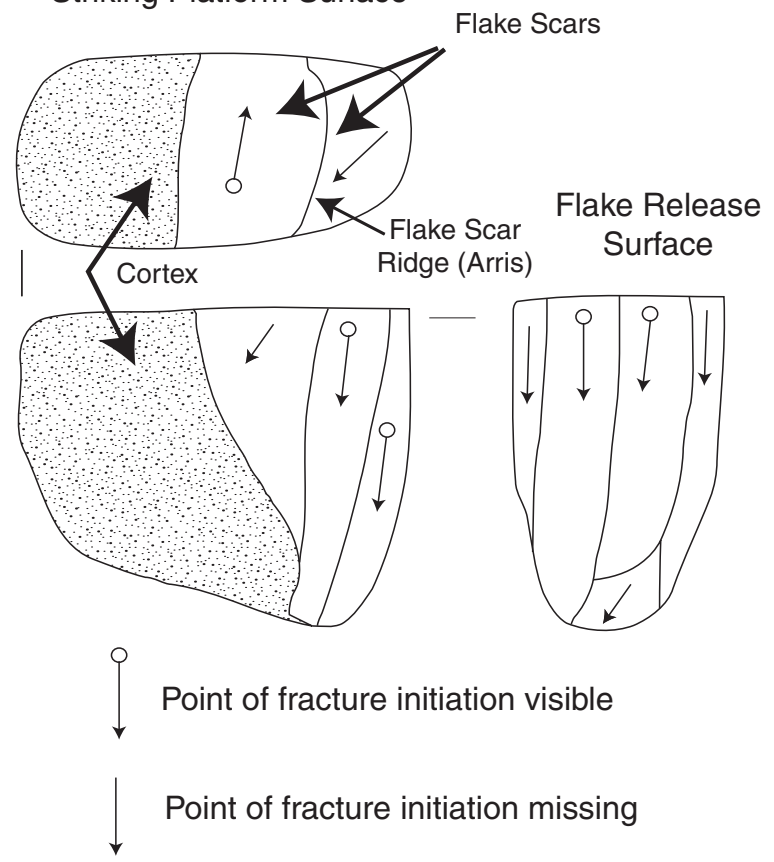

FIGURE 2.5. Core landmarks.

freshly fractured ventral surface and a dorsal surface that contains part of the former outer surface of a core (Figure 2.7). For purposes of description and orientation, the point of fracture initiation is said to be the "proximal" end of the flake. On a flake detached by Hertzian fracture initiation, this point can easily be identified by the presence of the Hertzian cone. As the fracture propagates away from its initiation point, the ventral surface becomes convex and then grows progressively flatter. The convex part of the ventral surface nearest the point of fracture initiation is called the bulb of percussion, or the bulbar eminence. Linear features, called "fissures" (or "lances"), and undulations on the ventral surface radiate away from the point of fracture initiation. If a Hertzian cone is absent, or if the striking platform is missing, lances/fissures and undulations provide additional clues to the point of fracture initiation.

The dorsal side of a flake is usually subdivided into a striking platform and the rest of the dorsal surface. The striking platform is the surface impacted by the hammerstone at the moment of fracture initiation. Its external platform angle intersects at $90^{\circ}$ or less with the 
Table 2.2. A Simplified Core Taxonomy (After Conard et al 2004, 14, Table 1)

\begin{tabular}{|c|c|c|c|}
\hline Characteristic & Inclined & Parallel & Platform \\
\hline $\begin{array}{l}\text { Position of main } \\
\text { flake-release } \\
\text { surface(s). }\end{array}$ & Broad surface & Broad surface & $\begin{array}{l}\text { Usually not a broad } \\
\text { surface. }\end{array}$ \\
\hline $\begin{array}{l}\text { Geometry and } \\
\text { number of } \\
\text { flake-release } \\
\text { surfaces. }\end{array}$ & $\begin{array}{l}\text { Volume defined } \\
\text { by two surfaces }\end{array}$ & $\begin{array}{l}\text { Volume defined } \\
\text { by two surfaces }\end{array}$ & $\begin{array}{l}\text { Volume defined by } \\
\text { more than two } \\
\text { surfaces }\end{array}$ \\
\hline $\begin{array}{l}\text { Angle of removals } \\
\text { relative to the plan } \\
\text { of intersection } \\
\text { defined by the } \\
\text { worked edge and } \\
\text { flake-release } \\
\text { surfaces. }\end{array}$ & Roughly $45^{\circ}$ & Less than $30^{\circ}$ & Not applicable \\
\hline $\begin{array}{l}\text { Removal angle } \\
\text { relative to the } \\
\text { striking platform. }\end{array}$ & Not applicable & Not applicable & Greater than $45^{\circ}$ \\
\hline $\begin{array}{l}\text { Orientation of } \\
\text { removals on the } \\
\text { main flake-release } \\
\text { surface(s). }\end{array}$ & $\begin{array}{l}\text { Converge toward } \\
\text { the center of the } \\
\text { removal surface(s) }\end{array}$ & $\begin{array}{l}\text { Multiple } \\
\text { possibilities }\end{array}$ & Parallel \\
\hline Origin of removals. & $\begin{array}{l}\text { All removals } \\
\text { originate from the } \\
\text { circumference } \\
\text { defined by the } \\
\text { intersection of the } \\
\text { two surfaces. }\end{array}$ & $\begin{array}{l}\text { All removals } \\
\text { originate from the } \\
\text { circumference } \\
\text { defined by the } \\
\text { intersection of the } \\
\text { two surfaces. }\end{array}$ & $\begin{array}{l}\text { Main removals from a } \\
\text { well-defined } \\
\text { striking platform } \\
\text { surface(s). }\end{array}$ \\
\hline
\end{tabular}

rest of the dorsal surface opposite the point of fracture initiation. Its interior platform angle (between the striking platform and the ventral surface) is usually greater than $90^{\circ}$. Archaeologists usually note whether the striking platform surface is cortical, plain, dihedral, or facetted because these conditions provide insights into core preparation. As with cores, archaeologists usually note whether the dorsal side of a flake has cortex and flake scars/ridges indicating previous flake removals. 

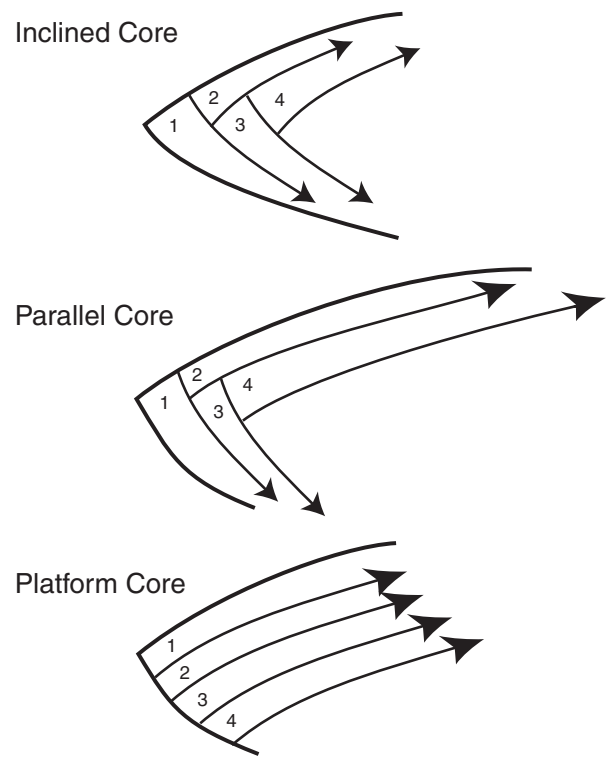

FIGURE 2.6. Working edges of major core types (inclined, parallel, platform) viewed in cross-section.
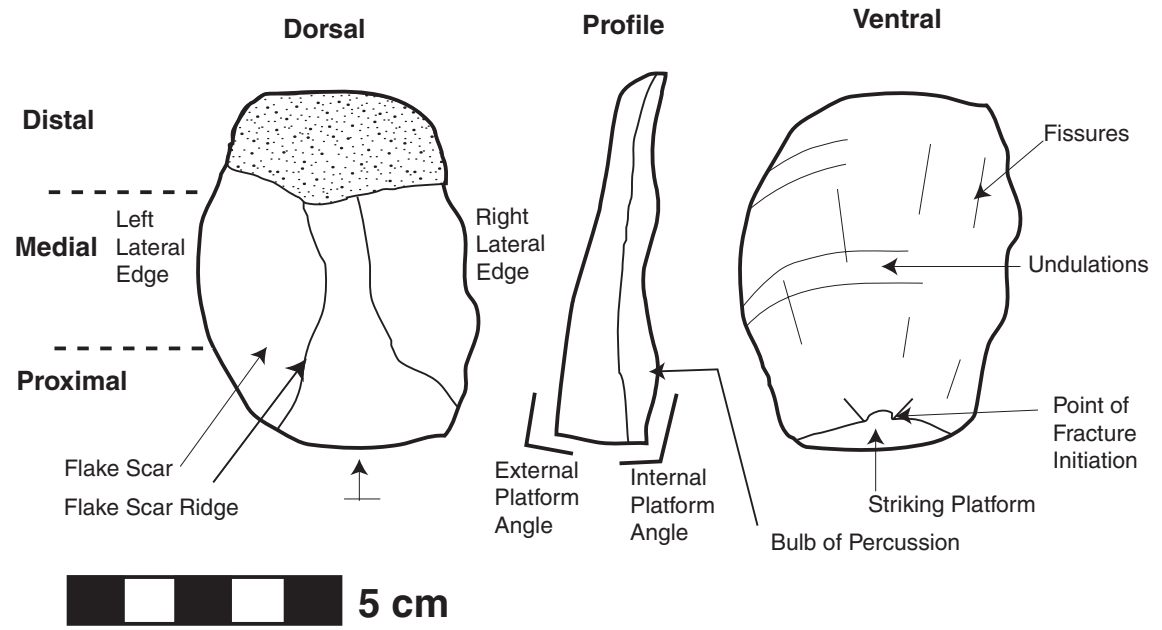

FIGURE 2.7. Flake landmarks.

Most classifications of unretouched whole flakes distinguish among cortical and non-cortical flakes, core-trimming elements, and blades (Figure 2.8). Cortical flakes are whole flakes with some remnant cortex on their dorsal surface. Greater proportions of cortical flakes and flake 
fragments in an archaeological lithic assemblage are thought to reflect initial stages of core reduction. Cobble fragments are cortical flakes that result from shear fracture of pebbles or cobbles.

Core-trimming elements (CTE) preserve a substantial part of a core's worked edge on parts of its dorsal surface other than in the immediate vicinity of the point of fracture initiation - that is, on the lateral or distal edges or the medial part of the dorsal surface. Some CTEs may reflect efforts to reshape, rejuvenate, or otherwise maintain a flake-release surface. Others may reflect knapping errors. CTEs are particularly valuable for research on prehistoric technological strategies because they reflect solutions to complex knapping problems (Boëda, Geneste, and Meignen I990).

Blades are flakes whose lengths are at least twice that of their widths. "Prismatic blades" are blades with straight lateral edges and dorsal flake scar ridges aligned disto-proximally. Historically, archaeologists have viewed prismatic blade production as a complex task worthy of particular notice, but recent years have seen challenges to this consensus (Bar-Yosef and Kuhn I999). A bladelet is a blade whose length is greater than or equal to twice its length, but not more than $50 \mathrm{~mm}$ long and whose maximum width is not more than $2 \mathrm{~mm}$.

When they are described at all, flake fragments are usually divided into proximal, medial, distal, or lateral fragments (Sullivan and Rozen I985). Unretouched flakes and flake fragments less than $20-25 \mathrm{~mm}$ long and considered too small to have been used as implements while held in the hand are often described as "debris." Whole flakes less than $20-35 \mathrm{~mm}$ long are sometimes described as "chips."

\section{Retouch and Retouched Tools}

The terminology for describing retouch varies somewhat between different phases of Levantine prehistory, but there are some consistencies (Figure 2.9). For most researchers, retouch, to be recognized as such, must run continuously for at least a centimeter along the edge of a tool, and it must extend onto a tool surface for more than $2-3 \mathrm{~mm}$.

Retouch can occur on one side of an edge (unifacial retouch) or both sides (bifacial retouch). The most common kind of retouch is unifacial retouch, which is usually located on the dorsal side of a flake. When unifacial retouch occurs on the ventral side of a flake, it is called "inverse retouch." When unifacial retouch creates a relatively sharp 

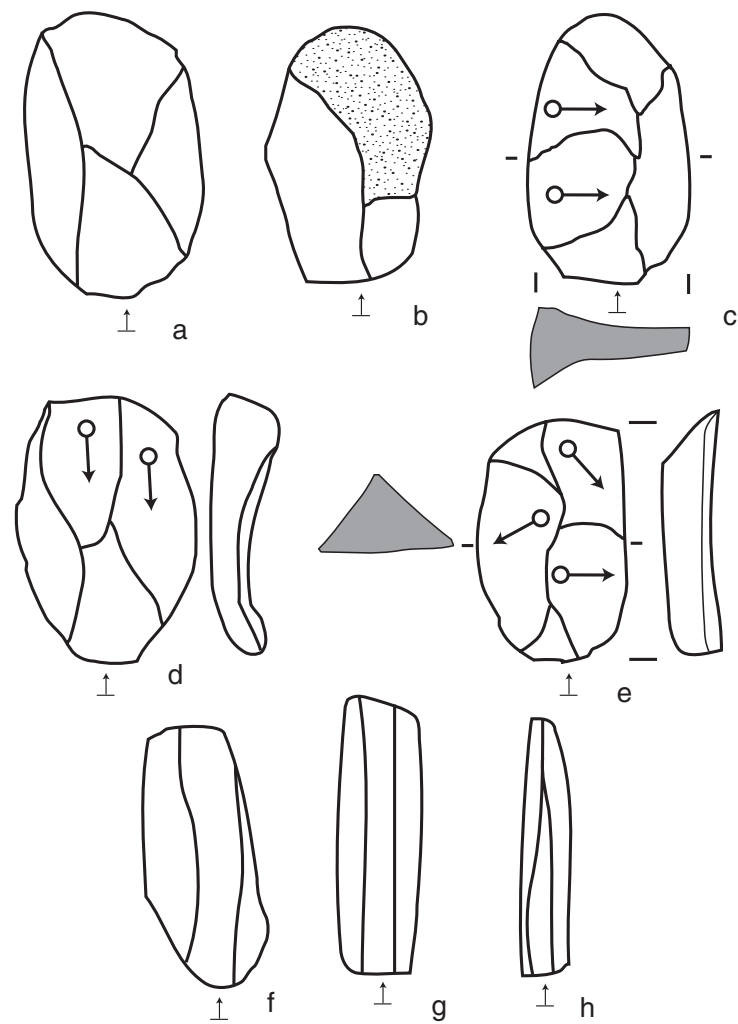

FIGURE 2.8. Major flake types. a. non-cortical flake, b. cortical flake, c. core-trimming flake-lateral, d. core-trimming flake-distal, e. core-trimming flake-medial, f. blade, $\mathrm{g}-\mathrm{h}$. prismatic blades.

edge $\left(<70^{\circ}\right)$, it is often called "scraper retouch." Backing is unifacial retouch with a steep edge-angle $\left(>70^{\circ}\right)$ located on the lateral edge of a flake. Truncation is backing applied to either the distal or the proximal end of a flake. Notching is unifacial retouch that creates a single large concavity on an edge. Denticulation is retouch formed by a series of small regularly or irregularly spaced concavities. Notching and denticulation grade into one another, with intermediate forms sometimes identified as "multiple notches." Invasive retouch is either unifacial or bifacial retouch that extends more than Io $\mathrm{mm}$ onto a flake surface. Burination is a form of retouch in which a flake is struck from a point or projection along the periphery of a flake so that the resulting fracture propagates parallel to an edge and more or 

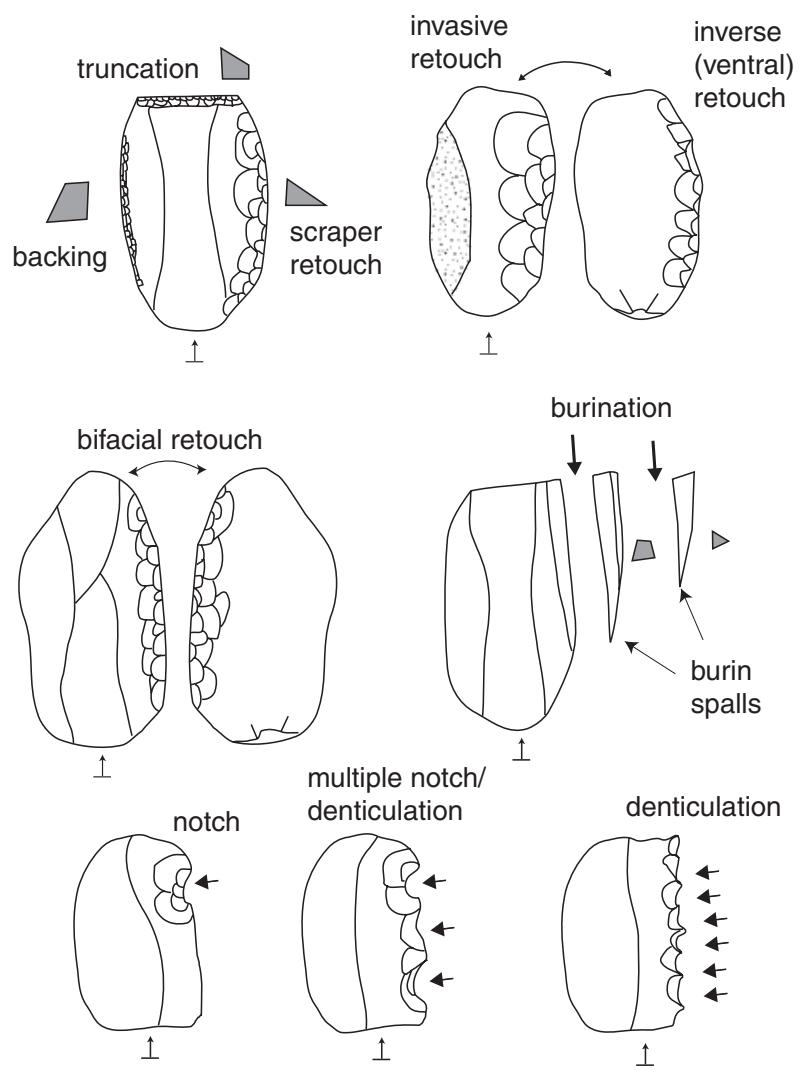

FIGURE 2.9. Retouch types.

less perpendicularly to the plane formed by the intersection of dorsal and ventral flake surfaces. The term burin (French for "chisel" or "engraving tool") refers to both the resulting scar pattern and the tool itself. The narrow elongated flake detached by this form of retouch is called a burin spall.

Retouched tools are flakes that have been modified by one or more kinds of retouch (Figure 2. Io.a-j). Scrapers are flakes with at least one unifacially retouched edge that is less than $70^{\circ}$ in profile. Truncations are flakes with a steeply retouched edge at either their distal or proximal end. Backed knives are flakes with steep unifacial retouch on their lateral edge. Awls are flakes with two relatively short retouched edges that converge to a point. Points are bilaterally symmetrical triangular 

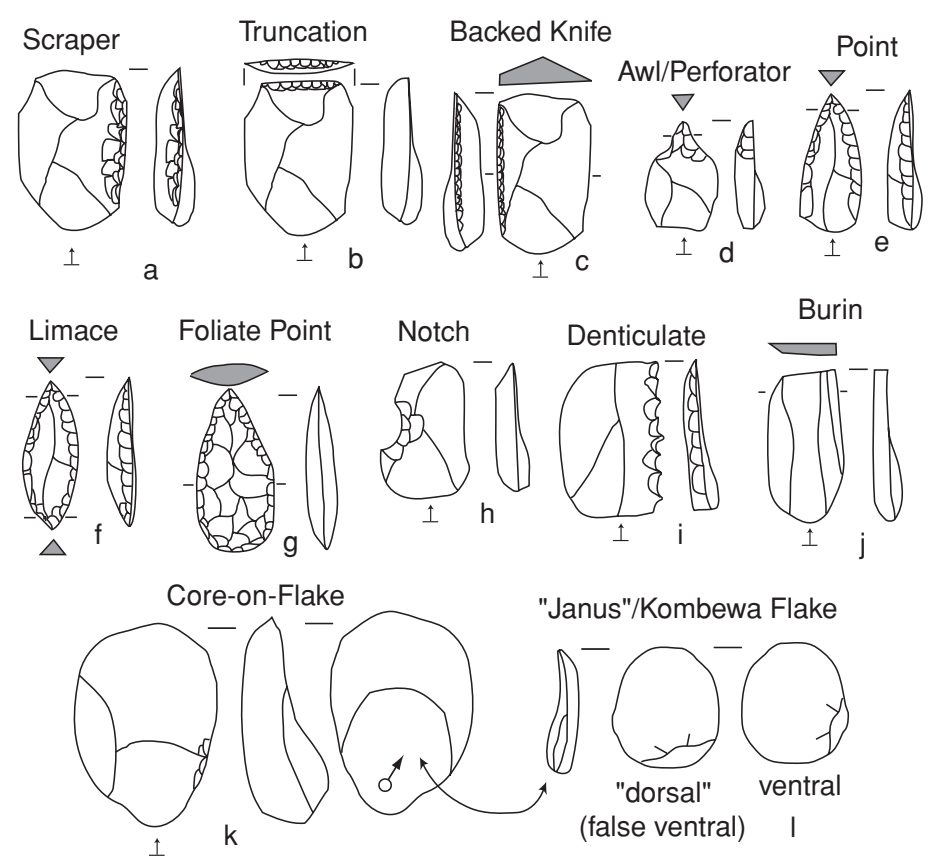

Ad hoc hammerstone on flake

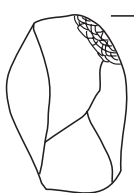

$\uparrow$

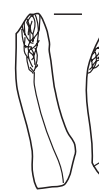

$\mathrm{m}$

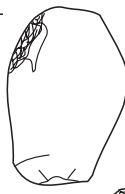

"Scaled piece"

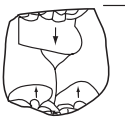

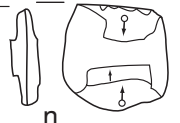

"Utilized" Flake

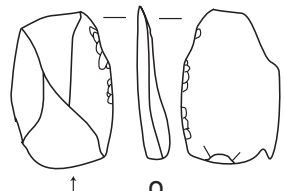

FIGURE 2.IO. Retouched tool types and problematical pieces. a. scraper, b. truncation, c. backed knife, d. awl/perforator, e. point, f. limace, g. foliate point, h. notch, i. denticulate, j. burin, k. core-on-flake, 1. "Janus"/Kombewa flake, m. ad hoc hammerstone on flake, n. "scaled piece," o. "utilized" flake.

flakes with retouched lateral edges that converge at their distal end. Foliate points (also known as foliate bifaces) are relatively thin pointed tools covered wholly or partly by invasive retouch. Limaces (French for "slug") are flakes with steeply retouched lateral edges that converge at both distal and lateral ends. Burins are flakes with one or more burin scars on them. Notches are flakes with one or more notched edges. Denticulates are flakes with one or more denticulated edges. 
Composite tools are retouched tools that combine the properties of more than one of these retouched tool types (e.g., scraper-perforator, burin-awl).

\section{Problematical Artifacts}

Some artifacts fit into more than one of the four major categories of lithic artifacts described in the previous subsection (see Figure 2. Io.k-o).

Core-tools are cores on which retouch has been applied to one or more edges. The key factor in differentiating these artifacts from cores is whether the retouch is focused on a discrete part of the tool edge. If not, then these fractures are usually interpreted as incidental damage accumulated in the course of flake production.

Cores-on-flakes are flakes that have had one or more relatively large scars detached from them, reflecting their use as cores. In principle, cores-on-flakes could be treated as cores, flake fragments, or retouched flakes. Most analysts treat them as cores. When the ventral surface of a flake was used as a flake-release surface, the resulting core and flake (which can appear to have two ventral faces) is called either a "Janus flake/core" (after the Roman god with two faces) or a "Kombewa flake" after a village in Kenya where early examples of these artifacts were observed (Leakey I936).

Ad hoc hammerstones are cores, flakes, flake fragments, and retouched tools that exhibit crushing, fractures, and other damage from use as a hammerstone. These artifacts are not usually classified as hammerstones, but instead as cores, flakes, flake fragments, or retouched tools incidentally damaged by use.

Scaled pieces (outils ecaillées or piéces esquillées in French) are flake fragments with one or more concentrations of invasive flake scars on dorsal and/or ventral surfaces. Scaled pieces are often treated as retouched tools, but similar kinds of damage can result from flake production (e.g., from using bipolar percussion on a flake or flake fragment) and from use (from using a stone flake as a wedge to split wood). They are increasingly viewed as byproducts of mechanical damage during tool use rather than as a deliberately shaped tool.

Utilized flakes preserve microfracturing along their edge that is thought to be too small and/or unpatterned to be retouch but large enough to indicate use-related damage. Such edge-damage usually 
extends no more than between $2-3 \mathrm{~mm}$ onto the dorsal or ventral side of an edge. Earlier descriptions of lithic assemblages often list utilized flakes as a distinct artifact-type. This practice is less common in more recent studies, reflecting a growing recognition that trampling, soil compaction, and other factors unrelated to tool use can create similar edge damage.

\section{Groundstone Tools}

Groundstone tools - artifacts shaped by carving and abrasion - often used alternation with percussion. The principal categories of groundstone tools are pulverizing equipment (grinding slabs, querns, handstones, mortars, pestles, etc.) used to process seeds, mineral pigments and other substances, celts (core-tools with polished working edges), stone vessels, and a variety of other perforated and incised objects. (Groundstone tools are rare in all but the latest Paleolithic and Neolithic contexts and are discussed more fully in Chapters 6 and 7.)

\section{Higher-Order Groupings of Lithic Artifacts}

Higher-order groupings of stone tools consist of a hierarchy of technological and typological characteristics, artifact-types, assemblagegroups/industries, and industrial complexes.

Groups of lithic artifacts that share similar morphological characteristics are called artifact-types. The attributes and variables archaeologists use to define artifact-types are usually divided into technological and typological characteristics. Technological characteristics are those related to choices of techniques and methods used in tool production. For example, the overall size of an artifact, the degree to which it has cortex, and its retouch reflect the choices of the raw material and the extent to which it has been modified. Typological characteristics reflect the imposition of arbitrary shape. Whether the tool is round, square, or triangular in plan view; whether retouch is unifacial or bifacial; and whether there are any patterns in the alignment of scars on the surfaces of the tool reflect choices toolmakers made among a range of functionally equivalent design options. Technological variables are generally thought to reflect differences in human adaptation, whereas typological variables are thought to reflect cultural differences among prehistoric toolmakers. This technology/typology 
dichotomy, however, is a false one. Technological choices (such as whether to use a particular tool or to retouch it) can reflect cultural differences, and variation in knapping techniques can influence tool morphology.

Lithic assemblages are groups of stone tools found in the same archaeological context. When more than one assemblage share similar inventories of artifact-types, they are often described as assemblagegroups or "industries" (Clarke I978). Industries from more than one major geographic region that differ typologically but share similar technological characteristics are called "industrial complexes."

Prehistorians use the term "culture" for lithic assemblage groups very sparingly. It is more common in Epipaleolithic and Neolithic periods when either (I) patterns of lithic typological variation are paralleled in other kinds of archaeological evidence, such as ceramics, architecture, bone tools, or personal adornments; or (2) variation in these other lines of evidence carry greater analytical weight than the lithic evidence. Archaeologists also use the term "tradition" for chronologically sequential assemblage-groups between which they perceive strong typological similarities. The terms "culture" and "tradition" imply that archaeological assemblage-groups correspond closely to social divisions among prehistoric humans. The terms "industry" and "industrial complex" have no such implications; they merely indicate similarities in prehistoric human adaptation related to stone tool technology.

Artifact-types and industries are often given proper names, usually derived from the site at which they were first identified. For example, the terms "Mousterian point" and "Mousterian Industry" are both derived from the French rockshelter, Le Moustier, where examples of Mousterian tools were first identified. Less commonly, the name for an artifact or an assemblage-group may be taken from a region in which the artifact or industry occurs, such as "Nubian core" or "Levantine Mousterian Industry."

Prehistorians often use type-lists and a variety of technological and typological indices to quantify inter-assemblage lithic variability. Type-lists differ between time periods. Appendix I provides type-lists for each of the major prehistoric periods discussed in this book. Most indices of lithic variability are simple ratios of one or more groups of artifact-types divided by some larger number of artifacts in an excavated lithic assemblage. These indices vary from period to period, 
and there are significant differences among researchers both in how these indices are computed and in how heavily they are weighted in debates about inter-assemblage variability. There are also indices based on metric variation among artifacts, also varying in computation and analytical use.

Ratio-scale measurements increase the quality of archaeological data and improve the kinds of hypotheses about prehistoric behavioral variability one can test with this evidence. Appendix 2 provides a guide to common measurements made on major groups of artifacts.

\section{INTERPRETIVE CONCEPTS IN LITHIC ANALYSIS}

Archaeologists have developed numerous theoretical concepts for interpreting variation among stone tools (Andrefsky 2005, Inizan et al. I999, Odell 2004). Before delving into the details of the Levantine lithic evidence, it is important to define and discuss the most important of these concepts.

Stone artifacts come to us as static entities, but they are products of dynamic behavioral processes. Linking static lithics to dynamic behavior requires one to correlate patterns of variation in the lithic record to variability in behavioral strategies. Strategies are solutions to a specific set of problems determined by the interaction of costs, benefits, and risks on evolutionary actors (Krebs and Davies I99I, Pianka I988). Modeling strategic variation involves hypotheses about the changing relationship between cost and benefit over time. The three most fundamental of these relationships are optimization (maximizing benefits per unit of cost), satisficing (obtaining minimally necessary benefits per unit of cost), and intensification (increasing costs in return for unchanging or declining benefits). The precise currencies of costs and benefits involved in various dimensions of lithic variability and how to measure them are much debated. Time, energy, and risk are obvious variables (Torrence I989, 200I), as they are for nearly all behavior, but other factors specific to stone tool technology involve utility (potential for continued use), versatility (potential for multiple uses), and portability (costs associated with transporting lithic artifacts).

Lithic artifacts pose some unique obstacles for strategic modeling. Unlike food or reproductive opportunities (the usual currencies of behavioral and evolutionary ecological models), the benefits of lithic technology are durable and transferable. That is, once a stone tool is 
made, it can be used by individuals other than its original author for years, decades, centuries, or millennia. Thus, the forms in which stone tools come to us from the archaeological record, both as an individual artifact and as artifacts in complex patterns of association, can reflect a complex overlay of individual strategic choices. In this, stone tools are like palimpsests, Medieval parchment manuscripts erased and writtenover many times.

Human behavior involving stone tools can be broken down into four major problems, each calling for different strategic solutions. These are raw material procurement, tool production, tool use, and discard/recycling. Many of the interpretive concepts archaeologists use to understand these behaviors are problematical, either because they dichotomize a complex continuum of behavioral variability or because they uncritically project what are likely recent aspects of technological variability into prehistoric contexts.

\section{Raw Material Procurement}

In writing about the procurement of lithic raw materials, archaeologists usually distinguish between local materials (those available within a day's walk of a site), and exotic materials available from further afield. Strategies for procuring lithic raw materials are discussed in terms of embedded and direct procurement (Binford I982, Kuhn I995). In embedded procurement, small quantities of raw materials are gathered in the course of daily foraging activities. In direct procurement, lithic materials are gathered in bulk from specific sources and transported to sites where they are modified and used. Archaeologists often equate local lithic materials with embedded procurement and exotic lithic materials with direct procurement. Reality can complicate these dichotomies. It is reasonable to assume that transporting lithic materials over great distances increased selective pressure for collecting high-quality materials. Consequently, archaeologists often assume that high-quality rocks represented in small quantities in a lithic assemblage are exotic. Although this might be correct, one needs to be alert to the possibility that they are local materials available only in small quantities. Similarly, embedded and direct procurement do not exhaust the range of strategies humans use to acquire lithic raw materials. Predictable patterns of residential site location and stable social 
relationships create incentives for more complex trade and exchange patterns, such as emissary trade and down-the-line exchanges. The Neolithic and later phases of Southwest Asian prehistory offer abundant evidence for such complex exchange strategies (Cann, Dixon, and Renfrew 1969).

In recent literature, archaeologists often draw a distinction between strategies for provisioning places and provisioning people with tools and raw materials (Kuhn 1993). Provisioning places involves transporting artifacts and lithic materials to habitation sites. The benefits of this strategy are contingent, delayed, and transferable. They accrue with prolonged and recurrent site occupations and persons other than those transporting materials can benefit from them. Provisioning people involves the creation and transport of personal gear. Provisioning people yields immediate benefits, and they are to a limited degree transferable, but they also entail costs, such as designing tools with high potential utility and functionally versatile designs. Archaeologists sometimes link particular types of stone tools to one or another of these strategies, but the actual relationship is almost certainly more complex. In large part, this is because strategic costs and benefits are continuously variable. An artifact that might make an appropriate choice as transported personal gear in one context might be prohibitively costly under a different set of circumstances. For example, while it might make sense to transport a two-kilogram core of high quality rock into a region impoverished in flint, this would be a poor strategic choice for a residential movement into a region where flint is underfoot nearly everywhere. Further complicating matters, traditional archaeological lithic systematics rarely distinguish artifacts on the basis of their size or mass, variables that are clearly germane to assessing their potential utility. Similarly, it is rare to see lithic raw materials described to greater precision than major rock types, such as flint/chert, limestone, basalt, or obsidian. There is, however, tremendous variation within each of these rock types, which affects their suitability for stone tool production.

\section{Tool Production}

Stone tools with useful cutting edges can be made in a matter of seconds or carefully knapped over the course of hours or longer periods. 
Archaeologists use the term "expedient" for the former tool-production strategy and "curated" for the latter. "Curation" can be confusing because it conflates optimization and intensification (Shott I996). Unnecessarily prolonged effort in tool production is a kind of intensification. Knapping in the service of recovering more potential utility from a given mass of stone is a form of optimization. It can be difficult to distinguish between the effects of intensification and optimization in the lithic record, because one can curate a stone tool by carefully shaping it to improve its functional efficiency, by resharpening it, by modifying it for novel uses, by transporting it, or by some combination of these activities.

In thinking about stone tool production, it is also crucially important to be alert to projecting modern-day habits of thought onto prehistory. For example, proponents of operational chain approaches to lithic analysis often dichotomize stone tool production in terms of façonnage (shaping a core-tool) and débitage (the production of flakes intended for use as tools) (see Inizan et al. 1999). No matter how well this dichotomy describes the thought processes of modern-day flintknappers and lithic analysts, it is a false dichotomy. The flakes detached in the course of shaping a core tool remain potentially useful tools (with or without subsequent modification) and the cores produced by flake production retain potentially useful cutting edges and surfaces.

That the stone tools we find are overwhelmingly ones made by adults in the service of their various economic and ecological adaptations is probably another backward projection of a recent (and largely Western) categorical distinction between adult work and child's play (Shea 2006a). Children are involved in tool production in many parts of the world today, and even where they are not, children learn many technical skills by imitation. Although it may be possible to differentiate the lithic output of children and other novice knappers in more complex lithic production sequences (Pigeot 1990), its presence may remain undetectable in simpler aspects of stone tool production.

Similarly, and although it is the case that ethnographic stone tool production is done mainly by men, the notion that prehistoric stone tool production was a gender-specific activity seems improbable (Gero I99I). Again, whether or not we can credibly detect gendered structuring of prehistoric lithic variation remains an open question. 
Much of the "culture history" of the Stone Age reflects perceived differences in stone tool designs and production techniques. Using these variables to construct quasi-historical entities, such as stone tool industries or archaeological cultures, potentially underestimates prehistoric toolmakers versatility and behavioral variability. Ethnographic stone-tool-makers vary their production techniques widely in response to seasonal differences in demands for tools (Thomson I939) and other factors, including shifts in their cultural landscape (see Shackley 2000). Many modern-day flintknappers can shift between widely differing modes of stone tool production (Whittaker 2004). Behavioral variability is a hallmark of hominin adaptation, particularly Homo sapiens adaptation (Potts I998, Shea 20I Ib, 20IIc). It is only logical to expect that such behavioral variability influenced variation in the archaeological lithic record from the earliest times onward.

\section{Tool Use}

When archaeologists speak of stone tool use, or function, they do so at differing levels of specificity. At the most basic level archaeologists often differentiate between "tools" (cores and retouched artifacts) and "waste" (unretouched flakes and flake fragments). Numerous ethnographic studies, however, describe the use of unretouched flakes (Holdaway and Douglas 20I2). Experimental studies verify their utility (Crabtree and Davis I968, Jones I980), and microwear analysis report evidence for their use in the past (Keeley 1980). This tool/waste dichotomy projects conventions of industrial-scale mass production back into the Stone Age.

At a further level of specificity, archaeologists speak of stone tool use as involving either extractive activities (food acquisition and other forms of energy capture) or maintenance activities (tool production and repair) (Binford and Binford 1969). They may also write of specialized versus multipurpose tools (Odell I98I). These categorical distinctions are also false dichotomies. Butchering an animal can both acquire food (meat and fat) and tool materials (bone, hide, or sinew). A tool designed for one narrow purpose can be co-opted into different purposes as circumstances require. For example, metal arrowheads used by Southwest African hunter-gatherers are also used as drills, knives, chisels, and woodworking tools (Wiessner I983). 
The expectation of strong form/function correlations among stone tools is a further obstacle to the development of in archaeological theory about stone tool use (Odell 200I). Many of the names archaeologists have given to specific artifact-types (such as "scraper," "burin," "projectile point," and the like) imply specific and consistent modes of use. This expectation makes sense in terms of present-day tool use. Most archaeologists live in sedentary societies and work in environments bristling with specialized tools. In more mobile ethnographic societies, tool designs place a greater emphasis on portability and functional versatility. Prior to agriculture, all hominin and most human societies likely practiced land-use strategies involving high residential mobility. For this reason, functional variability was likely the rule, and not the exception, for most of prehistory. Among residentially mobile groups, the main factor that constrains functional variability in stone tool use is hafting, which removes portions of tool edge from possible use (Keeley I982).

Sedentism may have reduced stone tool functional variability (Kelly 1992, Wallace and Shea 2006). Among sedentary groups, or ones with low residential mobility, fixed residential sites encourage the production of heavy specialized tools, such as seed-grinding equipment, because they are likely to be re-used at those sites. If stable residential sites were provisioned with large quantities of flaked stone, the wide range of stone tools' available sizes and shapes ought to have encouraged prospective tool users to select artifacts whose sizes, shapes, and edge configurations were better fits for particular tasks - leading to stronger form/function correlations.

\section{Discard/Recycling}

Archaeologists have long been aware that reuse and recycling influence lithic variability, particularly with variability among retouched tools and cores (Cahen, Keeley, and Van Noten 1979, Dibble I995, Frison 1969). Nevertheless, there persists in the archaeological literature a kind of "finished artifact fallacy," an assumption that the forms in which stone tools are preserved in the archaeological record reflect specific designs held in the minds of their makers (Davidson and Noble i993). In contrast, re-use, recycling, and allied phenomena 
affect nearly every dimension of recent human material culture (Schiffer 1987). All but indestructible stone tools persist on exposed surfaces and in the vicinity of habitation sites, available for use, for more prolonged periods. If anything, one might expect the effects of recycling/reuse to be even more pronounced among stone tools than in other dimensions of material culture.

\section{Social and Cultural Aspects of Lithic Variation}

In addition to these more pedestrian aspects of lithic technology, archaeologists have developed interpretive concepts linked to more esoteric aspects of social identity. Because the technological choices recent humans make are conditioned by factors relating to their social context, such as learned patterns of behavior and the social use of symbols, it is reasonable to expect similar factors to be at work in the prehistoric lithic record.

Style is a crucial concept in this regard. In its original formulation, style referred to cultural differences in technological choices, but the concept has since been parsed into iconological and isochrestic styles (Sackett 1982). Iconological style refers to information overtly incorporated into artifact designs for the purpose of broadcasting a specific message. Isochrestic style refers to patterned choices among functionally equivalent designs arising from learned patterns of behavior. They are not intended to actively broadcast a symbolic message, but they can provide clues about cultural similarities and differences among the people making those choices. Stone tools have the potential for both iconological and isochrestic stylistic variability. Conspicuous use of visually distinct exotic raw material might be a plausibly iconological aspect of stylistic variability. Backing the edge of a flake bifacially, as opposed to unifacially, might be a plausibly isochrestic style variant. Hypotheses that one or another stone tool is a stylistic marker of some prehistoric social entity have to be weighed against the simplicity of the technology involved and the improbability that identical patterns of variability could arise independently of one another. These probabilities are intuitively lower in earlier stages of tool production (in raw material choice and tool fabrication), and higher in later stages (in tool use and discard/recycling). 
Archaeologists read many things into the lithic record - chronicles of evolutionary progress, landscapes of cultural variation, and patterns of behavioral variability. At its core, however, the lithic record reflects variation in the habits of stone tool production and use. Archaeological lithic analysis seeks to reconstruct those habits and to explain their variability. 